\title{
EREBEA
}

Revista de Humanidades

y Ciencias Sociales

Núm. 3 (2013), pp. 195-201

ISSN: 0214-0691

\section{El caso VelázQuez. algunas reflexiones}

\author{
Bartolomé Bennassar \\ Universidad de Toulouse
}

Resumen

Estas páginas pretenden aportar algunas reflexiones acerca de la vida del pintor Velázquez, reflexiones que no se limitan al hombre-artista, sino que analizan la figura del Velázquez cortesano, el Velázquez cotidiano y el Velázquez como ser social, indagando, en lo posible, en sus relaciones con personajes coetáneos y con otros artistas de la época.

Palabras Clave

Velázquez; Biografía; Historia social; Historia de las mentalidades; Historia del arte.

Fecha de recepción: 2 de abril de 2013 Fecha de aceptación: 31 de julio de 2013

\section{Abstract}

The present essay gathers reflections on the various facets of the painter Velázquez. These facets are not limited to Velázquez the artist, but rather include as well Velázquez the courtier, the quotidian Velázquez and the social Velázquez. The essay thus explores the relationships Velázquez had with his contemporaries and with other artists in the period.
KEYWORDS

Velázquez; biography; social history; history of ideas; history of art 

Ilustrísimo sin ninguna duda, Diego Rodríguez de Silva y Velázquez, llamado comúnmente Velázquez, sigue siendo hoy día, si no un misterio (lo que sería exagerado sostener), sí un personaje difícil de conocer. Los historiadores, sean de Historia del Arte o de Historia General, desprovistos de documentos, cometieron errores, por otra parte muy comprensibles, casi lógicos.

Un ejemplo: muchos de ellos no dudaron en afirmar la hidalguía de la familia del artista y la suya propia. A partir de esta creencia, varios historiadores se maravillaron de la generosidad de espíritu de unos padres que supieron aceptar que su hijo (y más aún su hijo mayor) se dedicara al ejercicio de un oficio mecánico, es decir "vil", ya que el pintor se valía de sus manos para su oficio. Hasta que, corriendo el año 1999, un historiador sevillano, Luis Méndez Rodríguez, descubre que los abuelos maternos de Diego eran artesanos, calceteros exactamente, de manera que la pretendida hidalguía resultaba falsa. Así, los padres del pintor sólo habían permitido, de un modo lógico, a su hijo seguir su vocación, ejerciendo el oficio que más le convenía.

Pues bien, la dificultad para conocer y entender a Diego Velázquez procede de una ausencia excepcional de documentos. Veamos: ninguna correspondencia conservada, ni con sus padres, ni con Juana, su mujer (y es de suponer que la hija del culto Francisco Pacheco sabía leer), ni con su yerno, Juan Bautista Martínez del Mazo, ni con nadie; iy sin embargo tenemos las cuarenta y siete cartas de Francisco de Goya con su amigo Zapater! Tampoco conservamos su testamento. Velázquez, que volvió agotado de la Isla de los Faisanes, donde se había empleado con tesón en los preparativos de la boda de la infanta María Teresa con el futuro rey de Francia, Luis XIV, se acostaría enfermo y moriría sin tiempo de redactar o dictar su testamento. Y Juana, su esposa, que pasó de esta vida ocho días después, tampoco. Es decir que carecemos de cualquier documento escrito que exprese un deseo o una voluntad formulada por Diego Velázquez.

Podemos ańadir que el artista no fue miembro de ninguna cofradía, y que no tenemos contratos redactados con su anuencia o firmados por él, ya que un pintor del rey no se movía en el mercado del arte. Los únicos documentos que nos quedan -además, obviamente de los cuadros que son lo esencial- se limitan al inventario de los bienes del matrimonio Velázquez, llevado a cabo por su yerno y gran amigo Gaspar de Fuensalida; dentro de estos bienes, la librería del pintor, muy atípica para esta época y, por tanto, cargada de significado. 
Por suerte queda también la fama universal del pintor. En efecto, es su fama la que estimula la investigación, no sólo espańola, sino internacional, especialmente en el tercer centenario de su muerte (1960) y en el cuarto de su nacimiento (1999). El empeño de los investigadores, ayudados por empresas públicas o privadas, generaría coloquios, congresos y simposios que darían a conocer un sinnúmero de documentos, sin importancia de considerarlos individualmente, no así una vez clasificados. Pues dicha clasificación constituiría series que permitieron la edición de, por ejemplo, el Varia Velazqueña I y II de 1960 y el Corpus Velazqueño I y II del año 2000. La confrontación de todos estos documentos, muchos de ellos desconocidos, nos brindan hoy la oportunidad de conocer y entender algo más al genial artista sevillano.

En primer lugar descubrimos un "ser social", aunque esta aserción parezca sorprendente para algunos. Velázquez recibió a su suegra, María del Páramo, en su casa de Madrid, después de la muerte de su esposo, Francisco Pacheco, que viviría allí hasta su fallecimiento ocurrido dos años más tarde. Con su suegro, además, las relaciones fueron siempre buenas. Asimismo, Diego ayudó a sus hermanos; primero a Juan, que vino a Madrid, donde fue pintor, trabajando muy probablemente en su taller; luego a Silvestre, que residiría en su casa, muerto a los diecisiete años, y de cuyas exequias se encargaría Diego. También ayudó económicamente a sus padres, y con su esposa, Juana, dotó muy generosamente a su nieta Inés, cuando ésta contrajo matrimonio con un caballero napolitano.

Por otra parte entran en la lógica las supuestamente difíciles relaciones que Velázquez mantuvo con los pintores italianos del rey, especialmente Carducho, habida cuenta que aquéllos, celosos del rápido éxito del sevillano, siempre se mostraron muy desagradables con él. En cambio, sí mantuvo buenas relaciones con Angelo Nardi, otro pintor italiano del rey, más joven. Fueron excelentes sus relaciones con Alonso Cano, padrino de dos de sus nietas, con Francisco Zurbarán quien, según María Luisa Caturla, la gran especialista del pintor, debió a la intervención de Velázquez su participación en el Salón de las Bellas Artes del Retiro; igualmente con Bartolomé Murillo, a quien recibió en Madrid y a quien acompanó a ver las colecciones de pintura. Es decir, tuvo una red de amistades dentro del marco de su actividad artística y profesional. Y no olvidemos que el gran Rubens, cuando vino a Madrid por segunda vez, sintió gran simpatía hacia el joven artista, presintiendo su inmenso talento.

En los últimos años de su vida, Diego y Juana fueron padrino y madrina de varios niños hijos del personal de palacio, lo que demuestra que no vivían totalmente ajenos a la vida de la colectividad de la cual el pintor constituía una personalidad cada vez más relevante. Así un "ser social” que asistía a las fiestas palaciegas, a las corridas de toros y que, como tal, mantuvo relaciones de poder con superiores y subalternos, como es lógico no siempre agradables. 
Queda un interrogante importante. No hay manera de descubrir cómo fueron las relaciones entre los esposos; y la ausencia de cartas no ayuda. Los únicos documentos que tenemos, desprovistos lógicamente, por su naturaleza, de cualquier expresión de carińo, son los poderes que Diego dejara a Juana con motivo de sus dos viajes a Italia. Por otra parte se sabe que, durante el segundo viaje, prolongado durante dos años y medio, Velázquez mantendría una relación con una mujer, aún no identificada con seguridad, y de la que tendría un hijo. Pero se trata de una relación sobrevenida más de treinta años después de contraído su matrimonio, de modo que no puede brindarnos ninguna información a propósito de la vida anterior de la pareja. Diego y Juana tuvieron dos hijas muy pronto y ningún otro hijo después. Y no sabemos por qué.

En cuanto al trato privilegiado que el rey Felipe IV otorgara a su pintor -el único que hiciera su retrato, con la excepción de Rubens- a partir de 1623, con quien, durante ciertos períodos, se reunía cotidianamente en su taller, que trajo con él a Fraga en un episodio casi dramático en la vida del rey, es algo más que configura a Velázquez como un "ser social" y no como "un tipo raro" encerrado en su universo personal. Sea o no posible definir esta relación como una amistad entre el rey y el pintor, lo cierto es que estamos en presencia de una situación muy excepcional.

Quizás puede sorprender su actitud con su esclavo Juan de Pareja. No tanto por el hecho de poseer a un esclavo, cosa común en la época, sino por su actitud hacia quien quería desarrollar labores de artista. Velázquez le otorgaría su libertad, durante su segunda estancia en Roma, después de honrarle con un maravilloso retrato. Pero nunca favorecería la pasión de Juan de Pareja por la pintura, como si tal pasión, compartida por un esclavo, desvalorizase un arte que el pintor pretendía clasificar entre las Artes Mayores. Pequeñez de un gran artista.

Un "ser social”, sí. Pero también un hombre capaz de crear, que no quiso limitarse a ser artista y que pretendió seguir una carrera cortesana. En el siglo XVIII Palomino lo lamentó, pues, si Diego se hubiera consagrado enteramente a su arte, hoy día, en vez de gozar de unas, más o menos, cien obras maestras, podríamos contemplar, en los museos de Espańa o de cualquier otro, doscientos cuadros suyos, o más.

Porque, lejos de ser sólo un pintor de retratos como lo pretendiera Carducho, Velázquez demostraría su dominio de todo el registro de un pintor genial. Retratos sí, conforme a su cualidad de "pintor del rey", y el rey pudo admirar, por ejemplo, el famoso retrato de Fraga; pero también de la reina, de los príncipes hermanos de Felipe IV (así el infante Fernando, cazador), de los infantes e infantas. Pensemos en los maravillosos retratos de Baltasar Carlos a caballo y de la pequeña infanta Margarita.

Pero Velázquez no se limitó a la familia real; recordemos, entre otros, los retratos de Góngora, Quevedo, Demócrito, Pablillos de Valladolid, el Conde Duque, 
sin olvidar los del período sevillano, así el Aguador de Sevilla o la madre Jerónima de la Fuente. Y qué decir de los retratos inesperados de mujeres desconocidas, como los de la Dama del abanico y esa obra maestra del desnudo femenino, la Venus del Espejo. Y entre otros retratos fuera de serie, el del papa Inocente X y el del esclavo Juan de Pareja, los dos pintados en Roma.

Velázquez, sin embargo, fue mucho más que un retratista. En verdad, ninguna clase de pintura le sería ajena. Escenas mitológicas como La Fragua de Vulcano o, más tarde, las fabulosas Hilanderas, luego Mercurio y Argos; episodios bíblicos como La túnica de José. Cuadros históricos, tales como La Expulsión de los moriscos (quemado en el incendio del Alcázar) o la famosa Rendición de Breda (Las Lanzas). Y pintura religiosa ya bien presente en la época sevillana: La Adoración de los Magos, Cristo en la casa de Marta y Maria, y, ya en Madrid, el espléndido Cristo crucificado de San Plácido, La coronación de la Virgen o San Antonio Abad y San Pablo Ermitaño. A veces se divertía mezclando la fábula mitológica y los tipos populares; ;por eso un famoso cuadro suyo puede llamarse o bien El triunfo de Baco o más comúnmente Los borrachos! Sus paisajes, así los que rodean como los que envuelven a los príncipes cazadores, a Baltasar Carlos en su caballo, los planos de fondo de la Rendición de Breda como los dos cuadros romanos de la Villa Medicis, les han parecido a muchos críticos ya preimpresionistas por el uso de una técnica que desprecia las líneas duras y recurre a manchas ligeras, casi inmateriales, mezclando el cielo, las nubes, las montañas lejanas, los árboles, la hierba...

No me olvido de las extraordinarias Meninas, colección de retratos, cuadro histórico, escena de género y misterio para la crítica venidera. Así que con sólo un centenar de obras, todas las virtualidades de la pintura figurativa han sido ofrecidas por este artista al gozo de las generaciones de aficionados.

Ya se ha escrito. Velázquez quiso, también, seguir una carrera cortesana o palaciega, como se quiera. Pero el rey Felipe IV también lo quiso así, pues le pareció que el pintor tenía las capacidades suficientes para reordenar sus palacios y revisar su decoración. Por eso el rey le nombró en 1643 superintendente de obras y, en 1652, aposentador de palacio. Así Felipe IV pondría bajo su dirección y control la renovación del Escorial y del Alcázar. Y le envió a Italia, por segunda vez, con varias misiones, entre otras, la de comprar esculturas de la Antigüedad Romana o, caso de no poderse conseguir, contratar fundidores para obtener copias de algunas estatuas romanas de mármol, entre las mejores, una misión que Velázquez cumpliría con éxito, además de contratar a dos fresquistas de postín: Angelo Colonna y Agostino Mitelli, una vez que Pedro de Cortona renunció a hacer el viaje a España. Por desgracia, hoy en día no podemos aprovechar el resultado de esta misión pues El Alcázar, renovado con el extraordinario Salón de los espejos, desapareció en el incendio fatal de 1734. Es decir que perdimos no sólo obras del pintor sino, también, la demostración de su visión del palacio barroco que llegó a concebir. 
Algo más nos falta: la biblioteca de Velázquez. Atípica como ya apunté, casi carente de obras literarias y de literatura religiosa, pero en cambio repleta de literatura científica, italiana y española (Anatomía, Astronomía, Arquitectura, Matemáticas, Medicina, Náutica), lo que nos permite sospechar que Diego Velázquez fue un hombre apasionado por los misterios de la naturaleza, del cielo y de las estrellas, y de esta fantástica construcción que es el cuerpo humano. 
